\section{DESENVOLVIMENTO DE AUTOCONHECIMENTO E PROJETO DE VIDA NA ORIENTAÇÃO VOCACIONAL: UM RELATO DE CASO}

\author{
DEVELOPMENT OF SELF-KNOWLEDGE AND LIFE PROJECT \\ IN VOCATIONAL GUIDANCE: A CASE REPORT
}

\section{EL DESARROLLO DE AUTOCONOCIMIENTO E PROYECTO DE VIDA Y EN LA ORIENTACIÓN VOCACIONAL: REPORTE DE UN CASO}

RESUMO: A Orientação Vocacional (OV), quando realizada com adolescentes, estimula o autoconhecimento, a formação de habilidades, competências e conhecimentos requeridos para a elaboração de projetos de vida, inclusive promove suporte psicológico a esses sujeitos que enfrentam diversos desafios nessa etapa do ciclo vital. Nesta direção, relata-se um caso de OV cujo participante foi um jovem de 22 anos, matriculado em um cursinho pré-vestibular público. A intervenção teve caráter informativo e formativo, foi subsidiada por epistemologias construtivistas e socioconstrucionistas, almejou o desenvolvimento do autoconhecimento e a facilitação da construção de projetos de vida. Ao longo dos sete encontros 0 orientando conseguiu se perceber em uma trama de relações sociais as quais influenciam a constituição de seu modo de ser. À guisa de conclusão, a estrutura da OV praticada reuniu elementos da ordem clínica e educacional - tais características favoreceram 0 desenvolvimento de recursos pessoais para o planejamento e execução do projeto de vida do participante.

Palavras-chave: Orientação vocacional; Adolescência; Autoconhecimento; Processos reflexivos.

ABSTRACT: Vocational Guidance (OV) when carried out with adolescents encourages self-knowledge, the formation of skills, competences and knowledge required for the elaboration of life projects, including promoting psychological support to these subjects who face several challenges in this stage of the life cycle. In this sense, it's report a case of OV whose participant was a young man of 22 years old, enrolled in a pre-university preparatory course. The intervention had an informative and formative character, was subsidized by constructivist and socio-constructionist epistemologies, aimed at developing self-knowledge and facilitating the construction of life projects. Throughout the seven meetings, the student was able to perceive himself in a web of social relationships which influence the constitution of his way of being. As a conclusion, the structure of the OV practiced brought together elements of the clinical and educational order, such characteristics favored the development of personal resources for the planning and execution of the participant's life project.

Keywords: Vocational guidance; Adolescence; Self-knowledge; Reflexive process.

RESUMEN: LaOrientación Vocacional(VO) cuando se realiza conadolescentesfomenta elautoconocimiento, la formación de habilidades, competencias y conocimientos necesarios para la elaboración de proyectos de vida, incluyendo la promoción del acompañamiento psicológico a estos sujetos que enfrentan diversos desafíos en esta etapa del ciclo vital. En este sentido, se reporta un caso de Vo cuyo participante era un joven de 22 años, matriculado en un curso preuniversitario. La intervención tuvo un carácter informativo y formativo, fue subvencionada por epistemologías constructivistas y socioconstruccionistas, orientadas a desarrollar el autoconocimiento y facilitar la construcción de proyectos de vida. A lo largo de los siete encuentros, el alumno supo percibirse en una red de relaciones sociales que influyen en la constitución de su forma de ser. Como conclusión, la estructura de la VO practicada reunió elementos del orden clínico y educativo, características que favorecieron el desarrollo de recursos personales para la planificación y ejecución del proyecto de vida del participante.

Palabras clave: Orientación vocacional; Adolescencia; Autoconocimiento; Procesos reflexivos.

Recebido em 05/12/2019 Aprovado em 19/10/2020

\section{JOSÉ TADEU ACUNA}

Programa de PósGraduação em Psicologia do Desenvolvimento e Aprendizagem, Universi-dade Estadual Paulista (UNESP), Bauru, SP, Brasil 


\section{INTRODUÇÃO}

O atual modo de produção social, o capitalismo, impacta todas as dimensões da vida em sociedade. Com a globalização e as mudanças nas relações de trabalho, o mundo tornou-se liquefeito, no sentido de gerar rápidas transformações sociais e exigir das pessoas capacidade de se adaptar a estas inovações cotidianas. Neste contexto, muitas desigualdades econômicas, incertezas, questionamentos e contradições surgem, podendo gerar desconforto, conflito, até adoecimento psicológico àqueles que não conseguem acompanhar este modo de produção social (Bauman, 2001).

É possível perceber que, com o desenvolvimento tecnológico, novas profissões surgem, outras se modificam em seu fazer e algumas desaparecem. Taistransformações também exigem das pessoas conhecimento teórico e prático especializado em relação às suas atividades laborais, dessa forma, estimulam a busca por aperfeiçoamento individual e do desempenho da própria profissão. $\mathrm{O}$ resultado dessas mudanças no mundo do trabalho é o impacto em todas as dimensões da vida humana.

É comum na cultura atual que a educação esteja voltada à preparação dos indivíduos à entrada no mercado de trabalho. Desde os últimos anos da educação básica os jovens são orientados a decidirem sobre seus planos de vida, sofrem pressão para escolherem se ingressarão diretamente no mercado de trabalho ou se procurarão cursar uma graduação visando à formação em alguma profissão. Independentemente da escolha, o que está em jogo é a questão do trabalho. Andrade, Meira e Vasconcelos (2002, p. 6) afirmam:

$\mathrm{Na}$ sociedade globalizada, onde transformações se operacionalizam cada vez mais rapidamente, os jovens sentem-se pressionados, seja pela própria complexidade do mercado de trabalho, seja pelo avanço da tecnologia que indica novos rumos e caminhos a serem seguidos. Deve-se, também, levar em consideração que os jovens passam por um período conturbado em relação a aspectos maturacionais e de ordem psicológica, em que dúvidas emergem provocando confusões e conflitos.

A adolescência é um conceito socialmente construído e estabelecido para representar um período entre a infância e a idade a adulta, sendo comumente apresentado na literatura como um momento em que o indivíduo passa por diversos processos biopsicossociais (Dessen, Costa, \& Áderson, 2005), contudo, identifica-se instabilidade ${ }^{1}$ na definição de seu início e fim, por exemplo, no Estatuto da Criança e do Adolescente (ECA), Lei n. 8.069, de 1990, é indicado que a adolescência é representada pelos 12 anos completos e termina aos 18. Em estudo recente, Sawyer, Azzopardi, Wickremaranthne e Patton (2018) afirmam que atualmente ela se estende até os 24 anos. Por isso, para efeitos de normatização nesse estudo, utilizam-se os termos jovem e adolescente como semelhantes.

Quando se examina a adolescência é fundamental romper com concepções

1 Não se pretende discutir os determinantes etários da adolescência, nem se constitui como foco o estudo sobre as transformações biológicas, contudo, sabe-se que o funcionamento orgânico tem impacto na forma como o sujeito desempenha sua prática cotidiana. inatistas e biologizantes que compreendem esse período como uma fase determinada única e exclusivamente pelos aspectos orgânicos, tais como os efeitos dos desiquilíbrios hormonais na vida do adolescente (Bock, 2014). Na atualidade é recorrente que o jovem seja pressionado a assumir papéis sociais que anteriormente não tinha vivenciado, inclusive os de gênero, o grupo de amigos se torna importante em sua vida e a família que anteriormente, na infância, era seu centro de referência, passa a ocupar posição de menos destaque. 
Considerando os valores e representações sobre a adolescência, Lisboa e Soares (2018) apontam que no senso comum há ideias de que o jovem nesse período é mal-educado, tem problemas de comportamento e até envolvimento com drogas. Ademais, sofre com exigências culturais, tais como escolher uma carreira profissional bem-sucedida e a influência de discursos que tentam regular sua sexualidade. Todos esses elementos impactam diretamente a formação de sua identidade.

Bock (2014), Lisboa e Soares (2018) também ressaltam que, para o estudo da adolescência, é imprescindível considerar as condições socioculturais em que os jovens estão inseridos. Em uma sociedade capitalista existem grandes desigualdades sociais e de oportunidades, o processo de desenvolvimento do adolescente de classe média e alta é diferente daquele que se insere nas camadas menos favorecidas. Há jovens que precisam trabalhar para complementar a renda familiar, outros não têm acesso à educação de qualidade, atualmente, em contexto de pandemia causado pelo novo Coronavirus, muitos carecem de dispositivos e recursos para acessar a internet e acompanhar as aulas remotas e se prepararem para o vestibular. Essas diferenças e desigualdades se ampliam quando se reflete sobre os adolescentes com algum tipo de deficiência sensorial e/ou cognitiva, pois é recorrente serem colocados à margem do processo educacional.

Camargo, Feijó, Goulart, Campos e Cardoso (2018) pontuam que diante da grande complexidade e variabilidade do mercado de trabalho, no que tange às exigências para fazer parte do mesmo, o jovem pode se sentir pressionado e confuso para escolher qual caminho seguir, haja vista que escolher algo implica abdicar de outras possibilidades, bem como exige preparação para percorrer tal caminho. Para esse processo de escolha é demandado do adolescente conhecer seus interesses, inclinações, limites, possibilidades, enfim, é preciso que ele se reconheça inserido em uma trama de relações consigo mesmo e com o meio externo a ele.

É justamente neste âmbito que a Orientação Vocacional (a partir de agora OV) surge como possibilidade de facilitar ao jovem adolescente a passagem desta etapa da vida, favorecendo o desenvolvimento de projeto de vida que abrange suas escolhas e decisões tomadas ao longo de suas vivências e experiências (Levenfus, 2016). É oportuno mencionar que a OV, ao longo de seu desenvolvimento como prática de intervenção do profissional de psicologia e campo de estudo, recebeu outras denominações, por exemplo, Orientação Ocupacional ${ }^{2}$ ou Profissional e para o Trabalho, todavia, neste artigo, optou-se pelo termo Orientação Vocacional.

Super e Bohn (1980) afirmam que a OV é uma prática que vai além da preparação para a escolha de uma profissão; ela estimula os jovens a se conhecerem melhor na relação consigo mesmo e com seu contexto sociocultural com vistas ao desenvolvimento de qualidade de vida, por exemplo, ajudá-los a compreender a influência do meio em que vivem nas suas escolhas, de forma que essas possam ser mais autônomas e conscientes possíveis. Por outro lado, também contribui quando acolhe as angústias e frustrações que podem surgir ao longo do desenvolvimento do projeto de vida (Bock, 2014). Dessen, Costa e Áderson (2005, p. 16) advogam que a OV "cumpre sua função de extrema importância quando leva o sujeito a refletir sobre si mesmo, analisando suas características, explorando sua personalidade e aprendendo a escolher e abordar situações conflitivas".

Durante os processos de OV investigam-se os determinantes internos e externos das escolhas (Bock, 2014). Sendo os primeiros referentes à individualidade da pessoa, tais como autoconhecimento e particularidades pessoais, e os segundos representados pelas condições sociopolítico-econômicas vivenciadas, mundo do trabalho, a relação com a família e amigos. Neste sentido, o orientador reflete tais determinantes junto ao orientando, a fim de que ele tome consciência dos mesmos
2 Entende-se que existam diferenças entre as denominações, mas não é 0 intuito discuti-las aqui. 
e os articule com as suas decisões, preparando-o para vivenciar as mais diversas situações ao longo do caminho escolhido. Por isso, defende-se que a OV deve ter caráter informativo, possibilitando ao participante acesso às diferentes informações, seja sobre ele, a sociedade ou as relações sociais, inclusive também deve dispor de caráter formativo, especialmente no que tange à formação de novas habilidades e posturas diante da vida ou das demandas que surgem ao longo dela (Bock, 2014).

Bock sugere que o trabalho em OV deve ser realizado em algumas etapas. Primeira, o autoconhecimento com a finalidade de que os orientandos reconheçam quem são, seus interesses, modo de ser, ansiedades e perspectivas referentes a si próprios, de forma que esses elementos possam ser refletidos e debatidos, favorecendo a compreensão de sua influência nas escolhas e projetos de vida. A segunda envolve reflexões sobre a sociedade capitalista, o mundo do trabalho e o processo vestibular que permite abordar informações sobre as profissões e requisitos para a entrada no universo acadêmico. A terceira, desenvolvimento de projeto de vida a curto, médio e longo prazo, uma etapa em que o orientador articula os elementos discutidos nas etapas anteriores e traça com os orientandos estratégias para a satisfação de objetivos e sonhos de vida considerando os aspectos pessoais e da ordem social.

Quando se enfatiza os aspectos individuais do orientando na OV investigam-se e acolhem-se suas preocupações, angústias e medos com o objetivo de compreendêlos, e a partir disso elaboram-se planos de vida adequados às necessidades pessoais, inclusive, sendo possível empoderá-lo para enfrentar traumas e medos elaborados em seu passado (Soares-Luchiari, 1996). O trabalho a respeito de temas relacionados à família é comum e necessário, porque o exame dos aspectos familiares permite identificar tramas relacionais que envolvem aspectos subjetivos inconscientes os quais podem influenciar as escolhas profissionais.

Soares-Luchiari (1996) explica que reflexão sobre as conexões entre os participantes da rede familiar pode indicar projeções, no sentido de que os pais podem ser detentores de desejos e projetos que não conseguiram realizar outrora ou até mesmo de expectativas de que seus filhos se identifiquem com sua figura, sendo assim, depositam em seus filhos a incumbência da realização desses desejos. Tal projeção pode afetar a relação parental e provocar grandes pressões no jovem, que se sente impelido a escolher tentando conciliar suas vontades e não frustrar o desejo dos pais. Por isso, a autora supracitada defende ser impreterível o exame genealógico em intervenções de OV.

$\mathrm{Na}$ literatura sobre processos de OV nota-se a dinamização de diversas técnicas e a abordagem de variados temas com o intuito de auxiliar os orientandos no processo de escolha profissional. Sousa et al. (2014) reuniram quatro grupos de jovens aprendizes de uma organização não governamental de atuação municipal, a fim de refletir sobre suas escolhas e seus desdobramentos para seu futuro, considerando os seguintes tópicos: autoconhecimento, família e sociedade, relação entre mercado de trabalho e estudo.

Os autores supracitados durante os 12 encontros, que duraram cerca de uma hora e meia, recorreram às seguintes técnicas: confecção de crachás pessoais, que representavam sua individualidade; dinâmica do curtograma (Soares-Luchiari, 1993), a qual consistiu em preencher uma folha segmentada em quatro partes, a saber, gosto e faço, não gosto e faço, gosto e não faço e não gosto e não faço; aplicação nos participantes do instrumento, Avaliação dos Interesses Profissionais (AIP); questionamentos reflexivos sobre si mesmo; dinâmica dos sonhos, que consistiu na elaboração de procedimentos para o alcance dos desejos futuros. De acordo com os autores supracitados, "Os orientandos frequentemente relatam mudanças positivas de atitudes, frutos dos processos reflexivos oferecidos pelo projeto e das diferentes formas de pensar e de sentir" (Sousa et al., 2014, p. 14). 
Camps, Barcelos e Vaisberg (2014) realizaram atendimento clínico a sete adolescentes cujas demandas abrangiam medos, angústias e expectativas frente à escolha profissional. As autoras realizaram cinco sessões grupais em formato clínico, com duração de três horas cada; estavam subsidiadas pela teoria psicanalítica de base winnicotiana e recorreram à técnica de oficina terapêutica de criação, a qual, resumidamente, consistia em encenações nas quais os participantes deveriam representar suas tensões emocionais relacionadas ao processo de escolha profissional. Foram trabalhados medos acerca da não obtenção de sucesso e reconhecimento financeiro, preconceitos em relação a assumir papéis na sociedade e pessimismo frente ao atual panorama cultural. As autoras puderam notar que, após o acolhimento dos participantes e mediante os relatos ao longo da intervenção, eles se apresentavam preparados para enfrentar as tensões que o processo de escolha exigia.

Gonçalves (2019), subsidiada pela psicologia histórico-cultural, buscou preparar quatro adolescentes para o egresso da universidade e entrada no mercado de trabalho por meio de recursos artísticos e reflexões sobre as ansiedades e expectativas sobre esse momento. A autora discutiu que a OV realizada favoreceu a tomada de consciência sobre fatores subjetivos e objetivos que estavam gerando stress e ansiedade, inclusive foram construídas coletivamente estratégias de superação para tais condições.

Nascimento (2020) realizou um estudo de revisão narrativa de literatura sobre relatos de experiência de OV nas bases de dados SCIELO e BVS; dos 83 artigos levantados, nove relatavam práticas grupais com adolescentes e nenhum no formato individual. O autor supracitado discute que a partir da década de 1980 houve diversas reformulações teóricas e práticas na OV, a começar pela estratégia de intervenção que passou de atendimentos individuais para grupais, com orientação educacional a partir de atividades cujo objetivo eram de preparação, planejamento e implementação de projeto de vida e não somente para a escolha profissional em si.

Os estudos de Gonçalves (2019), Sousa et al. (2014), Camps, Barcelos e Vaisberg (2014) apresentaram formas de se realizar a OV no formato de atendimento grupal, inclusive Nascimento (2020) discute que há uma tendência em desenvolver práticas de orientação nesse formato coletivo a partir do final do século XX. Independentemente da metodologia empregada, nota-se que a OV favorece a construção de projetos de vidas mais autônomos e conscientes acerca dos determinantes que levam à realização das escolhas, inclusive estimula o desenvolvimento de habilidades e competências para o enfrentamento dos percalços que podem surgir ao longo do caminho escolhido e trilhado (Levenfus, 2016). Para tanto, advoga-se que desenvolver processos de OV com adolescentes é fundamental para sua saúde psicológica (Gonçalves, 2019).

Neste direcionamento, este artigo relata um caso de OV realizado com um adolescente cursante de um cursinho pré-vestibular público. Focalizaram-se as temáticas que emergiram ao longo dos encontros, a forma como elas foram abordadas, bem como as técnicas utilizadas com a finalidade de fornecer aos leitores e demais interessados no campo da OV uma metodologia para o desenvolvimento de práticas de orientação. Inclusive, pretendeu-se sanar essa lacuna na produção científica sobre intervenções no formato individual (Nascimento, 2020). 


\section{PROCEDIMENTOS METODOLÓGICOS}

Recorreu-se à metodologia de estudo de caso. Yin (2005) indica este tipo de método quando se intenta investigar com maior profundidade as especificidades de um contexto e seus sujeitos. Para isso, é necessário considerar o maior número de variáveis presentes no cenário. Também se caracteriza este estudo como qualitativo, pois ao longo do processo de OV o orientador tomou nota de relatos que considerou significativos e importantes para a reflexão junto ao orientando. Dessa forma, analisaram-se qualitativamente os sentidos e significados expressos durante os encontros.

A intervenção aconteceu em um município de pequeno porte do interior do estado de São Paulo onde se localiza uma universidade pública. A instituição oferta cursinho pré-vestibular à comunidade do município, sendo que as aulas são ministradas pelos estudantes dos cursos de biologia, medicina veterinária, administração e zootecnia nas dependências da própria universidade. Neste caso, a intervenção teve como local físico uma sala de aula na qual as disciplinas eram ministradas.

O autor deste artigo foi contatado pelo coordenador do cursinho para ministrar uma palestra sobre OV aos estudantes no segundo semestre do ano de 2017. Cabe pontuar que, por não ser o foco do artigo, não será abordada a descrição de tal palestra. Após a ministração, um dos estudantes do cursinho procurou o autor para tirar algumas dúvidas, aproveitou o ensejo e mostrou interesse em realizar o processo de OV. Neste sentido, o orientador e o orientando firmaram o compromisso de se encontrarem aos sábados, no período vespertino, das 14 às 16 horas. Neste primeiro contato firmou-se um termo de consentimento para a divulgação dos dados coletados em revistas, informando que os diálogos seriam gravados. Ademais, realizou-se o levantamento de necessidades de orientação, cujo resultado foi o interesse do orientando em autoconhecimento, receio e dúvidas sobre seu futuro profissional.

Convencionou-se nomear o participante de L. Na data em que ocorreu a OV, L tinha 22 anos, negro, natural do próprio município, cursou a educação básica em escola pública. Trabalhava como cabeleireiro em um estabelecimento comercial tradicional da cidade com mais de 20 anos de funcionamento ininterrupto. Mencionou que aprendeu o ofício aos 15 anos, com seu pai. Desde então começou a auxiliar seu irmão que também era cabeleireiro e aos 18 anos passou a realizar cortes masculinos. Afirmou que gosta muito dessa ocupação e pretende continuar até abrir seu próprio salão, mas gostaria de se graduar em licenciatura em Letras.

Ao todo foram sete encontros com duração de duas horas cada, ao longo dos meses de setembro e outubro. Sua estrutura foi segmentada da seguinte maneira: 15 minutos para o orientando relatar como foi sua semana e se as reflexões ocorridas no encontro anterior ocasionaram outras durante a semana; 80 minutos para reflexões e atividades sobre temáticas determinadas pelo orientador; 25 minutos para a revisão dos principais pontos trabalhados durante o encontro. Recorreu-se a materiais escolares para auxiliar no desenvolvimento das atividades.

Buscou-se subsidiar teoricamente o processo de OV a partir das epistemologias do Construtivismo e do Socioconstrucionismo. A primeira parte da premissa de que existe um mundo externo ao indivíduo, constituindo uma realidade concreta, porém, mediante as condições intrassubjetivas, ele interpreta esta realidade a qual ganha novas características e especificidades únicas (Grandesso, 2000). Em relação ao Socioconstrucionismo, tal epistemologia propõe que o conhecimento da realidade objetiva é fruto de um processo linguístico, uma produção cultural, ou seja, está na dependência dos significados compartilhados socialmente, os quais, 
por sua vez, orientam a interpretação do indivíduo sobre ele mesmo e seu entorno. Elkaim (1998, p. 229) diferencia ambas as posturas epistemológicas, afirmando que o construtivismo "está ligado ainda à tradição do individualismo, à medida que descreve a construção do saber a partir de processos intrínsecos ao indivíduo, enquanto o construcionismo social, ao contrário, volta-se para traçar as fontes da ação humana nas relações sociais".

Optou-se por seguir as orientações de Andersen (1991) no tocante ao desenvolvimento de processos reflexivos que favorecem a construção de novas formas de se pensar o mundo e a si mesmo. Neste sentido, foi trabalhado o autoconceito, entendido como "a percepção de nós mesmos, em condições específicas, incluindo nossas atitudes, sentimentos e o conhecimento acerca de nossas capacidades, habilidades, aparências e aceitabilidade social" (Noriega, Albuquerque, Alvarez, Oliveira, \& Coronado, 2002, p. 38). Além do autoconhecimento, compreendido como a capacidade do indivíduo em reconhecer e distinguir os elementos da ordem pessoal que influenciam seu pensar, sentir e agir consigo próprio e com o mundo ao seu redor (Levenfus, 2016).

Também se recorreu aos questionamentos reflexivos propostos por Grandesso (2000), os quais permitem a ressignificação dos valores pessoais e experiências dos indivíduos que se desdobram na elaboração de novas narrativas sobre si mesmo e o mundo à sua volta. De acordo com Frabetti, Thomazelli, Feijó, Camargo, e Cardoso (2015), o processo de elaboração de novas narrativas proporciona ao orientando a externalização das angústias, medos e dúvidas; por meio do diálogo com o orientador é possível transformar este cenário subjetivo em outro que seja favorável a ele, por exemplo, compreensão dos fatores que causam receio acerca do futuro, tendo em vista o fortalecimento de sentimento de autoconfiança.

Buscou-se fundamentar a aplicação das técnicas em autores que trabalham a OV na perspectiva sistêmica, tais como Levenfus (2016), Lisboa e Soares (2018), ou seja, as formas de condução do processo de OV foram adaptadas a partir desses autores. Além do mais, recorreu-se às seguintes técnicas: mapas das redes (Sluzki, 1996), dinâmica do curtograma (Soares-Luchiari, 1993), dinâmica do herói que examina processos de identificação (Levenfus, 2016), elaboração de projeto de vida, dinâmica "eu e minha família" objetivada mediante as contribuições teóricas de Soares-Luchiari (1993).

Também foram solicitadas duas tarefas, a primeira, elaboração de um diário de reflexões, pois tal como postulado por Bock (2014), o processo de refletir favorece a ampliação da consciência no sentido de identificar os determinantes da relação entre sujeito e o objeto a que se relaciona; particularmente, foi sugerido que L refletisse sobre seu próprio processo de OV, retomando as discussões e pontuando os avanços a respeito da compreensão de suas escolhas e elaboração de seu projeto de vida.

A segunda, solicitação de pesquisa mediada pelo orientador, visou ao estímulo do orientando no que diz respeito à expansão dos conhecimentos sobre seus próprios interesses profissionais a partir da consulta de informações sobre os requisitos de ingresso na faculdade e a estruturação de cursos de graduação que possivelmente gostaria de cursar. Mediante essa investigação, deveria levar dúvidas e questionamentos que seriam discutidos na sessão, possibilitando ao orientador elaborar sugestões e esclarecimentos sobre a inserção no mundo universitário.

Neste sentido, a estrutura do processo de OV se baseou no modelo triático discutido por diversos autores como Bock (2014), Lisboa e Soares (2018). Sinteticamente, (a) há um momento de desenvolvimento do autoconhecimento, (b) outro para a discussão e reflexão da relação do orientando com contextos próximos (família) 
e a cultura em que vive, (c) etapa de orientação e colaboração para a construção de projeto de vida que contempla a escolha profissional, considerando os requisitos objetivos e subjetivos para essa tarefa.

Os resultados do processo de OV foram sistematizados em uma tabela, de forma a apresentar as atividades realizadas nos sete encontros e os principais questionamentos reflexivos que conduziram a intervenção. Para a discussão dos dados colhidos privilegiou-se citar alguns trechos do relato do participante e correlacioná-los ao conjunto teórico apresentado neste artigo.

\section{RESULTADOS E DISCUSSÕES}

A intervenção realizada foi iniciada com o desenvolvimento do autoconceito e autoconhecimento. Retomou-se a história de vida do participante com o intuito de que ele refletisse sobre si mesmo, identificando as mudanças e transformações ocorridas em seu corpo e seu modo de ser ao longo do tempo, solicitando que buscasse justificativas para o que foi narrado. Também se dialogou sobre seus gostos e preferências a partir da aplicação do curtograma (Soares-Luchiari, 1993) e da apresentação de seu herói preferido por meio de desenho, desde que explicasse o motivo da escolha e correlacionasse com suas características e aspectos pessoais.

Organizou-se um encontro para que fosse refletido sobre as pessoas mais próximas com o intuito de identificar o lugar de importância das mesmas e o impacto afetivo em sua vida. Para isso, aplicou-se a técnica mapas das redes (Sluzki, 1996), cuja orientação foi para que o participante desenhasse em uma folha de sulfite círculos, um em volta do outro, e no centro escrevesse a palavra "EU”. Em seguida, deveria completar os círculos com nomes de pessoas respeitando a ordem: quanto mais próximo do "EU" mais importante e representativo seria em sua vida. Após esse momento, solicitou-se que L justificasse sua escolha tendo em vista o impacto daquelas pessoas em seu modo de ser.

Dedicou-se um encontro para o diálogo sobre a família. Para isso, pediu-se a L que levasse fotos de seus familiares e os apresentasse para o orientador. Questionou-se com quem ele mais se identificava, menos se identificava e o motivo de suas respostas. Ao final deste encontro solicitou-se duas tarefas: a primeira, L deveria elaborar um diário sobre as reflexões realizadas ao longo dos encontros, pontuando o que mais lhe chamou atenção, quais emoções surgiram e quais aspectos foram mais difíceis de se refletir. De forma geral, o participante deveria realizar um diagnóstico e avaliação sobre sua experiência em OV. A segunda tarefa consistiu em uma pesquisa orientada: L deveria escolher cinco profissões de interesse, buscar e ler o projeto político pedagógico ( $\mathrm{PPP}$ ) de cada curso e elaborar um relatório sobre como o curso era estruturado.

Dedicou-se um encontro para discutir sobre a tarefa de pesquisa. L apresentou o relatório e dúvidas que surgiram ao longo da investigação. Neste dia, orientando e orientador recorreram ao uso de mídias sociais e sites de universidades para investigar como cada curso estava estruturado, identificando suas características e o perfil exigido do corpo discente.

Por fim, foram reservados dois encontros para a reflexão de planos e projetos de vida. A dinâmica da árvore da vida, adaptada de Denborough e Ncube (2011), é uma atividade cuja tarefa é o desenho de uma árvore com todos seus componentes, a copa com as flores e folhas representava os desejos, o tronco, as habilidades, competências, conhecimentos e comportamentos necessários para alcançar o almejado e as raízes simbolizavam as pessoas e recursos necessários para suportar 
a trajetória em busca da realização dos sonhos. A continuação deste encontro foi o trabalho em conjunto entre orientador e orientando na construção do projeto de vida (Bock, 2014). É oportuno mencionar que, nesse momento, ocorreu uma ação diretiva de aconselhamento por parte do orientador, respeitando as vontades, necessidades, limites e possibilidades do orientando. A seguir, o quadro sintetiza o que foi trabalhado ao longo do processo de OV.

Quadro 1: Atividades desenvolvidas por encontro

\begin{tabular}{|c|c|c|}
\hline Encontro & Atividade & Questionamentos reflexivos \\
\hline $\mathbf{1}^{\mathbf{o}}$ & Retomando minha história de vida & Quem eu fui? Quem eu sou? Quem eu posso ser? \\
\hline $\mathbf{2}^{\mathbf{o}}$ & $\begin{array}{c}\text { Aplicação do curtograma; } \\
\text { meu herói }\end{array}$ & $\begin{array}{c}\text { O que eu faço e gosto? O que eu não faço, } \\
\text { mas gostaria de fazer? O que eu faço, mas não } \\
\text { gostaria de fazer? Quem é meu herói favorito? }\end{array}$ \\
\hline $\mathbf{3}^{\mathbf{0}}$ & Mapas das redes & $\begin{array}{c}\text { Quem são as pessoas mais próximas e que } \\
\text { influenciaram/influenciam meu jeito de ser? }\end{array}$ \\
\hline $\mathbf{4}^{\mathbf{0}}$ & Eu e minha família & $\begin{array}{c}\text { Quem é sua família? Quais as semelhanças entre } \\
\text { você e ela? Com quem eu mais pareço? }\end{array}$ \\
\hline $\mathbf{5}^{\mathbf{0}}$ & $\begin{array}{c}\text { Apresentação da tarefa } \\
\text { dirigida sobre profissões }\end{array}$ & $\begin{array}{c}\text { Quais as características das profissões? } \\
\text { Como são os cursos de graduação? }\end{array}$ \\
\hline $\mathbf{6}^{\mathbf{0}}$ & Árvore da vida & $\begin{array}{c}\text { Quais são meus sonhos? O que é necessário fazer } \\
\text { para realizá-los? Quem pode me apoiar? }\end{array}$ \\
\hline $\mathbf{7}^{\mathbf{0}}$ & Elaboração de projeto de vida & $\begin{array}{c}\text { O que eu desejo a curto, médio e a longo prazo? } \\
\text { O que é necessário saber/fazer? }\end{array}$ \\
\hline
\end{tabular}

Fonte: Elaborado pelo autor

Os quatro primeiros encontros visaram ao trabalho dos aspectos relacionados ao autoconhecimento. As reflexões se iniciaram sobre quem o orientando era, suas características e qualidades, focando em si próprio e sua história. As discussões se orientaram no sentido de que fosse possível reconhecer que sua identidade é construída mediante a relação com os outros (Bock, 2014). Com essa estratégia, o orientando conseguiu relatar diversos conteúdos, inclusive chegou à conclusão de que é importante olhar para o passado para se entender o presente. Em suas palavras:

Agora eu percebi, meu pai sempre foi bravo comigo, mas gostava muito de mim, por isso deixava as coisas todas arrumadas em casa! Até hoje eu gosto de organização! Agora entendi... que esquisito! Parece que as coisas são um ciclo, né?

As atividades "meu herói" e "eu e minha família" permitiram o trabalho com identificações. De acordo com Levenfus (2016), explicitar processos de identificação e refletir com o orientando sobre os motivos que o aproximam do identificado permite discutir sonhos, desejos e expectativas sobre si mesmo, além das qualidades que gostaria de ter, permitindo assim um momento para a discussão de sua história pessoal e possíveis ações que poderiam colaborar na construção de um modo de ser que se aproxime da figura desejada.

O orientando conseguiu refletir sobre a ideia de que seus gostos indicam aspectos sobre seu modo de ser. Ao se identificar com o herói The flash, questionou-se sobre a vontade de realizar suas tarefas com maior agilidade e eficácia, sendo que este desejo foi construído mediante as pressões vivenciadas em seu trabalho e comentários de seus amigos. Em suas palavras:

Nova Perspectiva Sistêmica, v. 29, n. 68, p. 91-104, dezembro 2020. 
Agora eu entendi! Essa vontade de ser rápido parece que é para compensar isso... eu tenho um ritmo mais lento, sou muito calmo! As pessoas sempre são tão agitadas, fazendo várias coisas ao mesmo tempo... lá no salão, como tem muita gente, tem que fazer tudo rápido... essa pressão me cansa!

Diante dessa narrativa, foi necessário discutir sobre os padrões culturais de desempenho educacional e social. Dialogou-se sobre a modernidade líquida, a objetificação das relações interpessoais e a necessidade de se apresentar um padrão de beleza imposto socialmente (Bauman, 2001). Foi debatido que todas essas exigências sociais e modelos veiculados pela mídia são incorporados pelas pessoas, no sentido de tomarem como verdade e caminho a ser seguido tal como se fosse uma norma preestabelecida. Inclusive, foi argumentado pelo orientando que quem não compactua com esses valores geralmente é estigmatizado, que, de acordo com suas palavras, recebe a qualificação de "estranho".

A temática família também surgiu como uma segunda instituição que exerce grande influência no pensar, sentir e agir das pessoas (Soares-Luchiari, 1996). O orientando elaborou a seguinte reflexão, a partir da discussão desse assunto:

É pressão de todo lado por parte do meu pai, você tem que ser bom e bonito em tudo... exigem que eu faça vários cortes de cabelo, exigem isso, exigem aquilo! Tem hora que parece que vou explodir, não é fácil isso! Por isso que tem vez que eu quero sumir do mundo!

Identificou-se uma certa resistência do orientando em refletir sobre a família e seus componentes. Em seu relato frisou apenas a figura paterna, o irmão e a mãe foram apresentados rapidamente sem mais informações. O orientador tentou estimular o diálogo sobre essas questões, mas L evitou discutir sobre esse assunto; por vezes olhou no relógio dizendo que precisaria ir embora mais cedo. Soares-Luchiari (1996) afirma que a investigação sobre os aspectos familiares pode fornecer pistas para o entendimento de traumas e bloqueios psicológicos, os quais podem ser trabalhados de forma a fortalecer os indivíduos para enfrentar temáticas consideradas difíceis e dolorosas. No entanto, devido à disponibilidade de tempo e objetivo da intervenção, apenas se orientou a L que, caso houvesse interesse em discutir com profundidade sobre a temática família ou alguém em específico, haveria possibilidade. $\mathrm{O}$ orientando concordou e prosseguiu com as atividades.

Apesar do fato de que esse ambiente de tensões familiares não foi debatido no processo de OV relatado, pois se optou por respeitar a vontade do orientando, notou-se que a questão da mãe e do irmão apresentou certa pressão, a ponto de ser aversiva à discussão. Soares-Luchiari (1996) discute que o orientador deve abordar tal temática justamente para estimular o enfrentamento de representações que causam incômodo psicológico, inclusive investigar o quanto elas influenciam nas indicações de possíveis escolhas profissionais. De outra forma, Frabetti et al. (2015) sugerem ser importante explorar novas narrativas acerca de si mesmo e das relações que circulam o orientando, para que consiga ressignificar representações que possam causar angústias ou tristezas a ele, ou seja, compreender o conteúdo subjetivo de outra forma que não cause algum tipo de pesar.

Ao final do quarto encontro, o orientador solicitou duas tarefas, sendo que o diário de reflexões deveria ser um material de consulta própria, sua apresentação era facultativa. Porém, a pesquisa sobre as profissões seria realizada e comentada no encontro seguinte. Neste direcionamento, discutiu-se sobre a graduação em cursos de Direito, Letras, Psicologia, Biologia e Jornalismo. Recorreu-se à rede social 
Facebook para pesquisar sobre tais cursos. Durante o diálogo L afirmou que nunca tinha pensado em consultar o PPP das graduações e que essa atividade sanou várias dúvidas e o aproximou do curso de Letras, em suas palavras:

O curso de Letras tem mais a ver comigo, vendo os grupos no facebook notei que tenho mais a ver com as pessoas que fazem letras! Eu gosto de ler, gosto de demorar mais (risos)! Eu posso fazer este curso aqui na cidade à noite e na hora em que não estou trabalhando.

$\mathrm{O}$ orientador questionou o motivo dessa declaração e L justificou que não pretendia abdicar de seu trabalho, haja vista que ajudava seu pai com as despesas da casa. Em relação à indicação do curso de Letras, L não explicou de forma aprofundada, mas mencionou que gostava de ler nas horas vagas e escrever trechos de poemas. Ao ser questionado sobre esse posicionamento, se mostrou encabulado e preferiu mudar de assunto, mesmo assim, o orientador tentou novamente abordar tal questão, mas L se mostrou resistente e preferiu não continuar o diálogo sobre isso. Foi respeitada a posição do orientando.

Nos últimos dois encontros, o orientador facilitou a construção do projeto de vida do orientando. Mediante a apresentação do desenho da árvore da vida (Denborough \& Ncube, 2011), elaboraram uma estrutura que favoreceu a tomada de decisões por parte de L. Foi orientado a ele que utilizasse uma pasta catálogo segmentando-a em três partes nomeadas respectivamente de: planos a curto, médio e longo prazo, sendo que em cada divisória colocaria suas reflexões escritas em folhas; poderia também elaborar desenhos e reunir outros tipos de materiais.

Foi explicado que esse material o auxiliaria a organizar seus pensamentos e estabelecer metas para a conclusão dos objetivos pessoais.

Sugeriu-se a L que recortasse tiras de papel sulfite para que nelas fossem escritas as seguintes questões: $\mathrm{O}$ que eu preciso saber para realizar meus sonhos? O que eu preciso fazer? Quem pode me ajudar? O que não depende de mim para a realização dos objetivos? Essas tiras coloridas deveriam ser coladas na capa da pasta catálogo. Por fim, esses questionamentos reflexivos (Grandesso, 2000) foram utilizados na discussão entre orientador e orientando com o intuito de auxiliar na formulação de seu projeto de vida e formas de conquistá-lo.

É oportuno mencionar que durante esta atividade o orientando realizou um processo de síntese, retomando as discussões dos encontros anteriores no tocante à identificação dos motivos de suas vontades. L mencionou que não gostaria que seus sonhos fossem divulgados ou qualquer informação relatada por ele nestes dois encontros, pois era algo muito pessoal. Neste sentido, respeitou-se a vontade do orientando.

No transcorrer do desenvolvimento do processo de OV, L se reconheceu como sujeito inserido em uma trama de relações, conseguiu perceber que ele se constitui mediante a interação com o outro. De fato, este é um dos intuitos de se trabalhar o autoconhecimento em OV. Bock (2014) afirma que quando os indivíduos percebem com o que se identificam, discriminando suas particularidades e singularidades, ocorre a ampliação de sua consciência, que favorece condições psicológicas para a organização e execução de planos e projetos de vida de forma mais realista e preparada para o enfrentamento das dificuldades que por ventura surgirão no caminho.

O trabalho com o autoconhecimento também favoreceu um contexto catártico em que o orientando pôde externalizar suas angústias diante das pressões vividas (Levenfus, 2016). Para isso, foi necessário dialogar sobre como a sociedade está estruturada e as formas normativas de se pensar a respeito do desempenho pessoal

Nova Perspectiva Sistêmica, v. 29, n. 68, p. 91-104, dezembro 2020. 
no modo de produção capitalista. Segundo Bauman (2001), vive-se um momento em que a aparência é valorizada em detrimento do que as pessoas realmente são. Existe a busca por uma perfeição aparente que pode gerar constantes pressões aos indivíduos, pois ao tentarem responder a tal padrão podem estimular o abandono de suas próprias vontades e sentimentos, sendo que tal contexto pode levá-los ao adoecimento psicológico.

Refletiu-se sobre as declarações que L fez sobre as exigências postas pelo pai, especialmente sobre realizar cortes com maestria e velocidade. Acreditou-se que essa demanda sobrecarregava o orientando de forma a deixá-lo angustiado. Pelo seu relato, entendeu-se que tinha uma carga horária extenuante, haja vista que várias vezes mencionou que trabalhou até às 20 horas do dia que antecedia o encontro com o orientador.

Outro fator a se atentar foi a questão da ausência de relatos sobre momentos de lazer e relacionamentos afetivos. Inferiu-se que $L$ não dispunha de tempo para isso, sendo este outro fator que poderia gerar tensão psicológica. Além do mais, conjecturou-se que o enredo familiar estava voltado à reunião de capital e à manutenção do status social, afinal, a barbearia em que trabalhava era conhecida por receber pessoas influentes na política da cidade. Todos esses fatores socioeconômicos foram entendidos como elementos que pressionavam $\mathrm{L}$, inclusive contribuíam na formação de uma personalidade introvertida, tal como se mostrava.

Com a tomada de consciência de alguns determinantes internos e externos da escolha, aliada à atuação do orientador, a qual facilitou a construção de narrativas sobre si mesmo e o mundo mediante o fornecimento de informações sobre como deveria se pesquisar a respeito de cursos de graduação, o orientando pôde identificar maior interesse no curso de Letras. Bock (2014) sugere que o orientador deve exercer um papel de facilitador durante o desenvolvimento de processos de OV, pois informar ao jovem como, onde e de que forma poderá obter informações sobre profissões é o primeiro passo para auxiliá-lo a escolher a carreira que mais se adéque ao seu perfil, considerando seus gostos, habilidades e condições biopsicossociais.

Por fim, infere-se que os questionamentos reflexivos (Grandesso, 2000) permitiram a L aprimorar a capacidade de raciocinar e buscar relações de causa, efeito e finalidade, sendo que isso foi possível de constatar quando estabeleceu relações entre passado, presente e futuro durante a elaboração de seu projeto de vida. Foram vários os momentos em que ele apresentava verbalizações do tipo: “ $a h$ ! Agora eu entendi! Parece que uma coisa lá de trás está ligada com a outra de agora! Eu percebo que tenho certas vontades e não me permito por medo bobo...". Inclusive, ao longo do processo de OV, suas habilidades sociais de expressão de sentimentos e assertividade foram se ampliando, pois, ao final da intervenção, se comunicava com mais firmeza e desenvoltura. Contudo, essas são impressões pessoais do orientador.

\section{CONSIDERAÇÕES FINAIS}

O exame da OV realizada permitiu reconhecer contribuições teórico-práticas a essa área de atuação profissional. Ao trabalhar aspectos clínicos, o orientador acolheu narrativas de cunho pessoal que expressavam angústias e medos frente a uma etapa da vida; considerando a sua atuação, o orientando ressignificou tais narrativas de forma a se fortalecer e preparar para trilhar seu caminho da forma mais autônoma e segura possível. A atuação educacional promoveu a formação do sujeito, estimulou a capacidade de pensar e ampliou seus recursos pessoais para a concretização de seus sonhos. 
Sendo assim, finaliza-se este estudo de caso de OV indicando que é possível realizá-la a partir de uma perspectiva clínica e educativa, inclusive, tal proposta se apresenta interessante e atual para o trabalho com adolescentes que vivenciam diversos desafios nesta etapa da vida, pois a partir dessa estrutura de intervenção é estabelecido um canal de acolhimento de demandas da dimensão afetiva, empoderamento para o enfrentamento das exigências da sociedade capitalista, formação de habilidades e competências para elaboração de projetos de vida de forma mais autônoma e assertiva.

\section{REFERÊNCIAS}

Andersen, T. (1991). Processos reflexivos. Rio de Janeiro: Instituto Noos.

Andrade, J. M., Meira, G. R., \& Vasconcelos, Z. B. (2002) O processo de orientação vocacional frente ao século XXI: perspectivas e desafios. Psicol. Cienc. Prof., Brasília, 22(3), 46-53.

Bauman, Z. (2001). Modernidade líquida. Rio de Janeiro: Jorge Zahar.

Bock, S. D. (2014). Orientação profissional: a abordagem sócio-histórica. São Paulo: Cortez.

Camargo, M. L., Feijó, M. R., Goulart, E., Campos, D. C., \& Cardoso, H. F. (2018). Experiências de estágio em Psicologia Organizacional e do Trabalho e Orientação Profissional: conexões entre teoria e prática no mundo do trabalho. Araraquara, SP: Letraria.

Camps, C. I. C. D. M., Barcelos, T. F., \& Vaisberg, T. M. J. A. (2014). Atendimento ser e fazer e escolha profissional: Estudo sobre eficácia clínica. Boletim de Psicologia, 64(140), 21-32.

Denborough, D. \& Ncube, N. (2011). Atendendo crianças que vivenciaram traumas: a árvore da vida. Nova Perspectiva Sistêmica, 39, 92-101.

Dessen, M. A., Costa, J.g \& Áderson, L. (2005). A ciência do desenvolvimento humano: tendências atuais e perspectivas futuras. Porto Alegre: Artmed.

Elkaim, M. (1998). Panorama das terapias familiares. São Paulo: Summus.

Frabetti, K, C., Thomazelli, C., Feijó, M. R., Camargo, M. L., \& Cardoso, H. F. (2015). Práticas Narrativas e Orientação Profissional: a possibilidade de desconstrução de estereótipos ligados às profissões. Nova Perspectiva Sistêmica, 24(53), 41-55.

Gonçalves, E. C. V. (2019). A orientação profissional enquanto promotora de saúde mental na adolescência: um relato de experiência. Trabalho de Conclusão de Curso, Graduação em Psicologia, Universidade Federal de Uberlândia, Uberlândia, MG.

Grandesso, M. A. (2000) Sobre a reconstrução do significado: uma análise epistemológica e hermenêutica da prática clínica. São Paulo: Casa do Psicólogo.

Lisboa, M. D. \& Soares, D. H. P. (2018). Orientação Profissional em Ação: formação e prática de orientadores ( $1^{\text {a }}$ ed.). São Paulo: Summus.

Levenfus, R. S. (2016). A orientação vocacional em contextos clínicos e educativos. Porto Alegre: Artmed.

Nascimento, L. R. (2020). Orientação Profissional na interface entre Psicologia e Educação: uma revisão de literatura. DOXA: Revista Brasileira de Psicologia e Educação, 22(1), 5-20.

Noriega, J. A. V., Albuquerque, J. B. de J., Alvarez, F. L., Oliveira, L. M. S., \& Coronado, G. (2002). Autoconceito em uma população do nordeste brasileiro. Revista PSICO, 33(1), 37-52.

Sawyer, S. M., Azzopardi, P. S., Wickremaranthne, D., \& Patton, G. C. (2018). The age of adolescence. The Lancet: Child \& Adolescent health, 2(3), 223-228. 
Sluzki, C. E. (1996). La rede social: frontera de la practica sistemica. Barcelona, ESP: Gedisa Editorial.

Sousa, R. J. G., Feijó, M. R., Camargo, M. L., Campos, D. C., Goullart, E., \& Cardoso, H. F. (2014). Projeto de Extensão Universitária em Orientação Profissional (OP) para jovens: uma parceria entre universidade e instituição formadora de aprendizes. Raízes e Rumos, 2(2), 1-11.

Soares-Luchiari, D. H. (1993). Pensando e Vivendo a Orientação Profissional. São Paulo: Summus.

Soares-Luchiari, D. H. (1996). Os desejos familiares e a escolha profissional dos filhos. Revista de Ciências Humanas, 14(20), 81-92.

Super, D. E. \& Bohn, M. J. (1980). Psicologia ocupacional. São Paulo: Atlas.

Yin, R. K. (2005). Estudo de caso: planejamento e métodos ( $3^{\mathrm{a}}$ ed.). Porto Alegre: Bookman.

\section{JOSÉ TADEU ACUNA}

Psicólogo, pedagogo. Mestre e doutorando em Psicologia do Desenvolvimento e Aprendizagem. Atualmente desenvolve pesquisas em Psicologia Social, Psicologia Escolar e Educacional.

https://orcid.org/0000-0002-3359-6395

E-mail: tadeuacuna@gmail.com 